\title{
Ripple Orientations on Martian Dunes Document Diverse Wind Flow Patterns
}

James R. Zimbelman, Molly B. Johnson, Jennifer O'Brien Center for Earth and Planetary Studies, National Air and Space Museum

Smithsonian Institution, Washington, DC 20013-7012
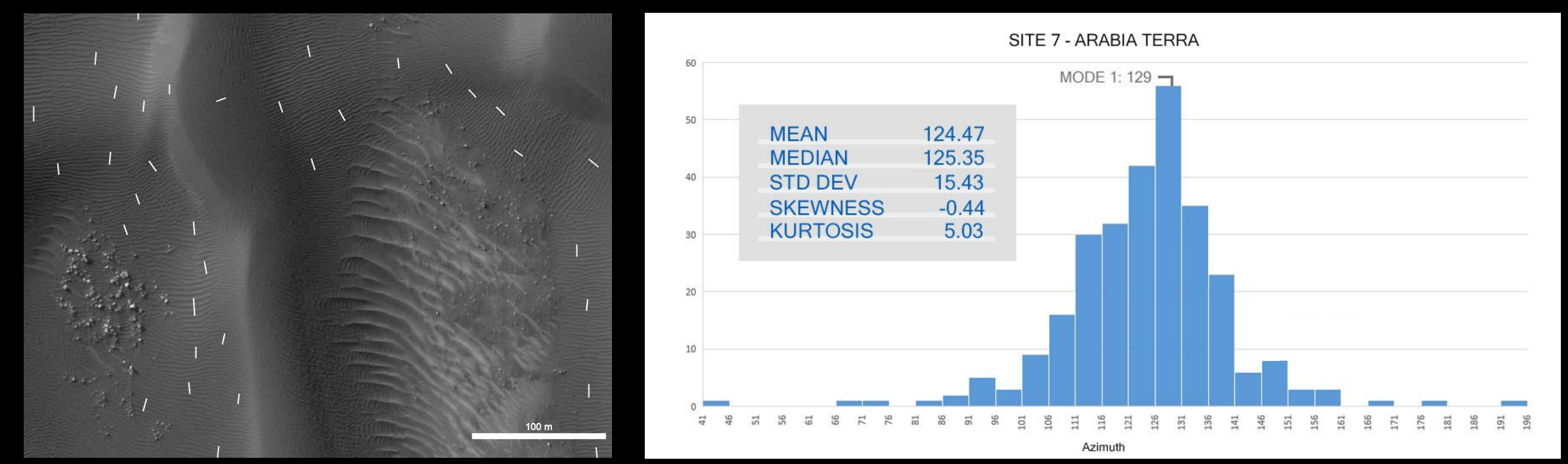
40 study sites were examined; 7 with JMARS, 33 with ArcGIS

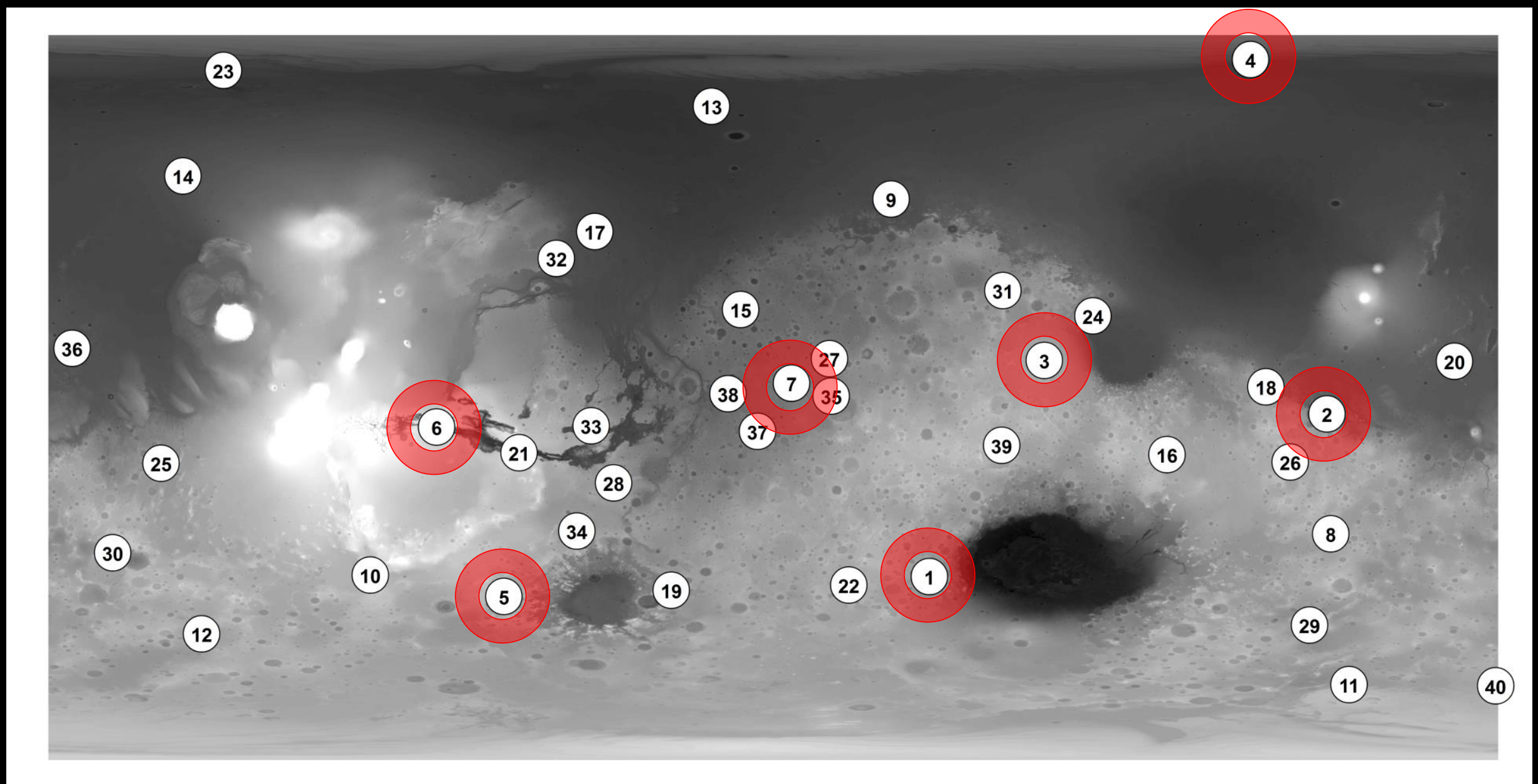

Here we present results from the first 7 locations, measured using JMARS software MDAP grant NNX12AJ38G 


\section{Ripples Mapping Procedure}

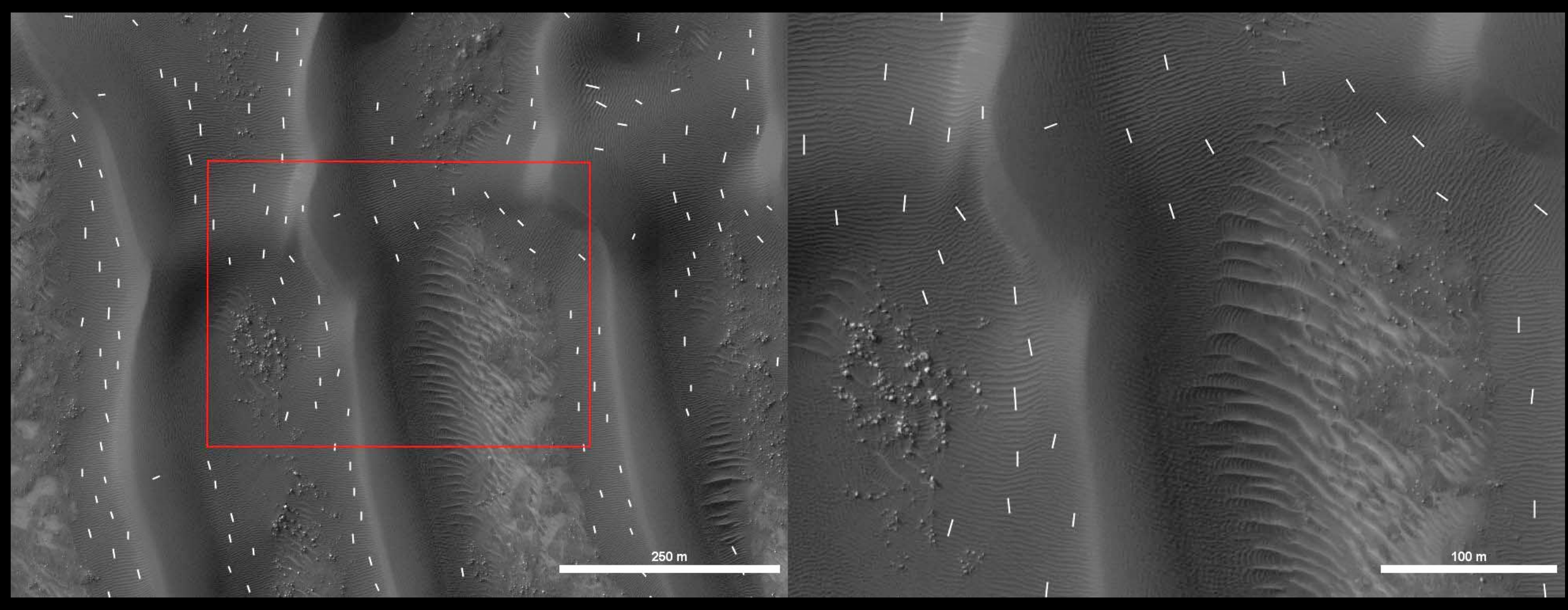

- Only Small Dunes (small or no slip face) - Avoid places with superposed ripples

- Avoid places near slip face, if present

- Draw line perpendicular to crest, (crests of three adjacent ripples) 


\section{Statistical 'Moments' of a Distribution}

"Moments are the sums of the integer powers of the values"

Mean - First moment; value around which clustering occurs

Variance - Second moment; 'width' or 'variability' around mean

(Standard Deviation is square root of the variance)

Skewness - Third moment; degree of asymmetry around mean

Kurtosis - Fourth moment; 'peakedness' or 'flatness' relative to

a normal (Gaussian) distribution ( $\mathrm{K}=3$ )

Median - value for which larger and smaller values are equally probable Mode - value where distribution is a maximum

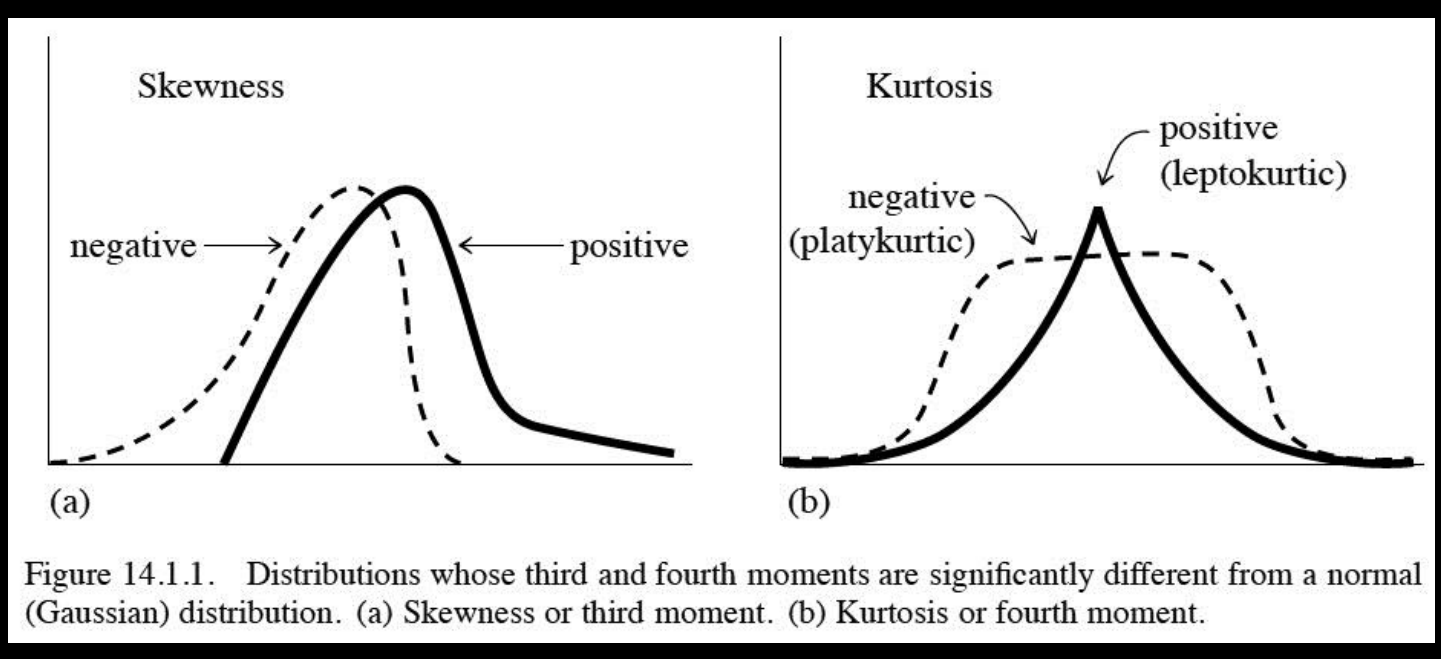

Numerical Recipes in C: The Art of Scientific Computing, 1992, Cambridge Univ. Press, pp 610-615. 


\section{2 - Gale Crater}

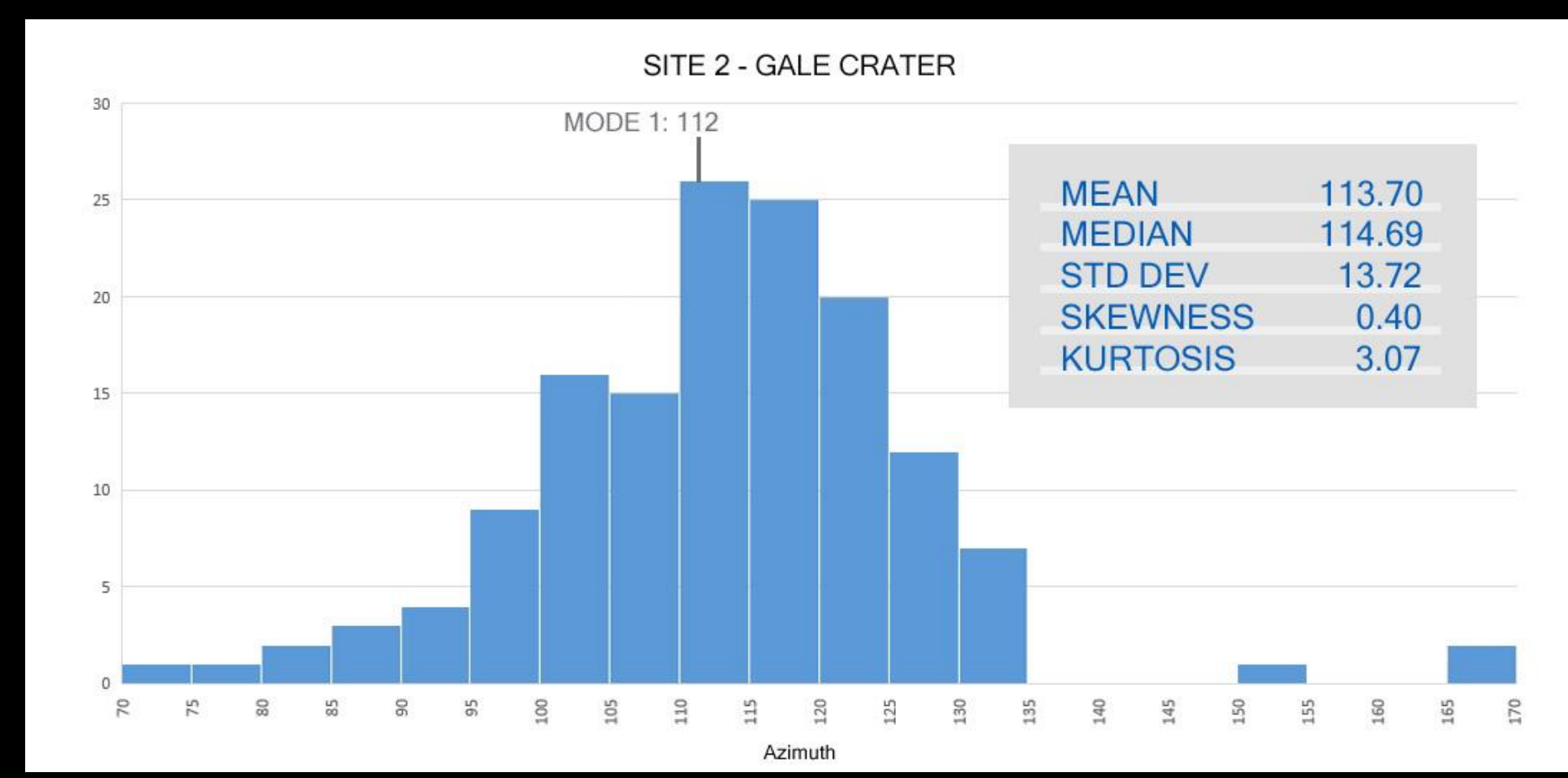

$n=144$

Unimodal

Longitudinal, barchanoid

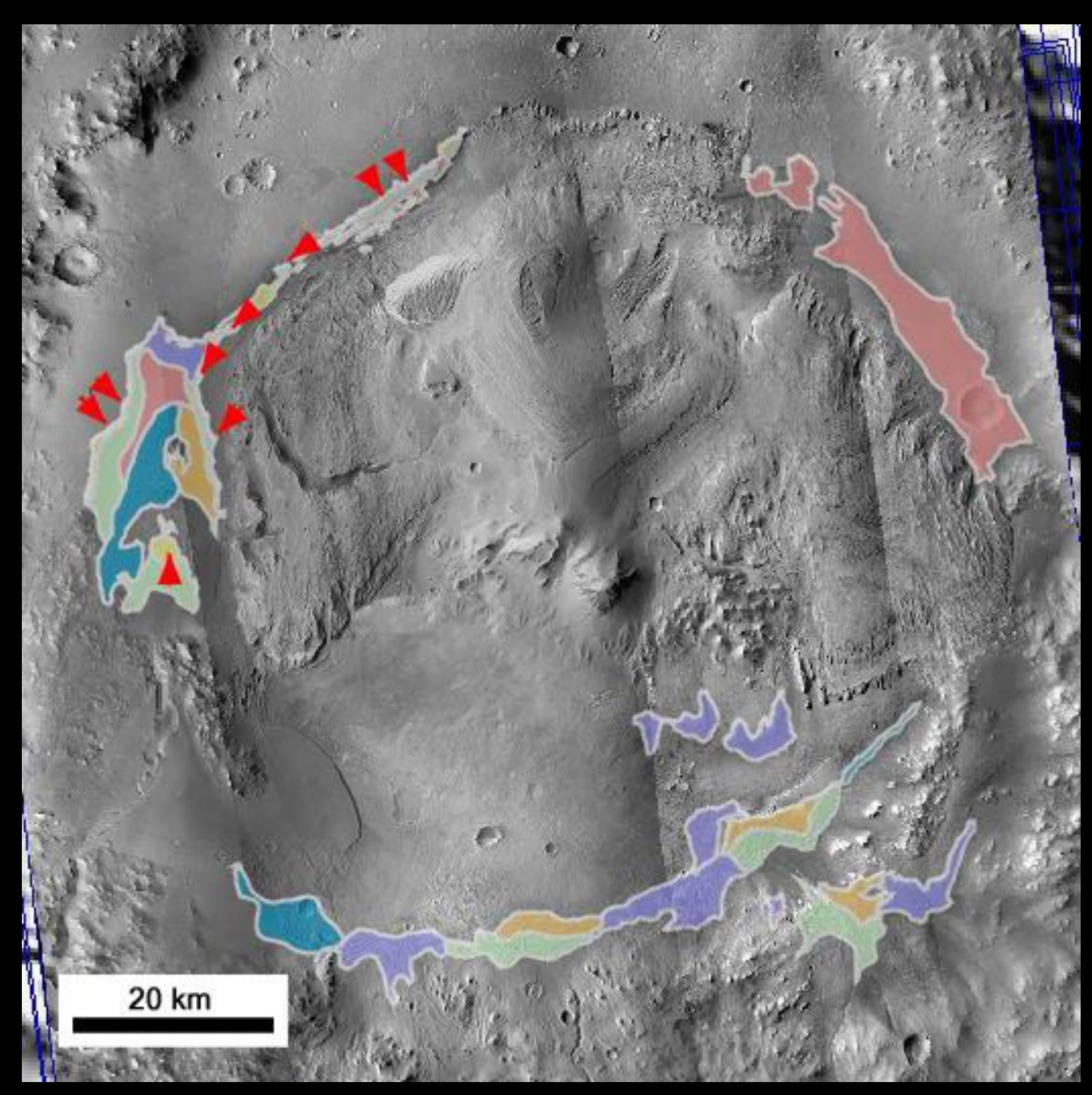

Regional map by Y. Ku (CTX images) 


\section{4 - North Polar Erg}

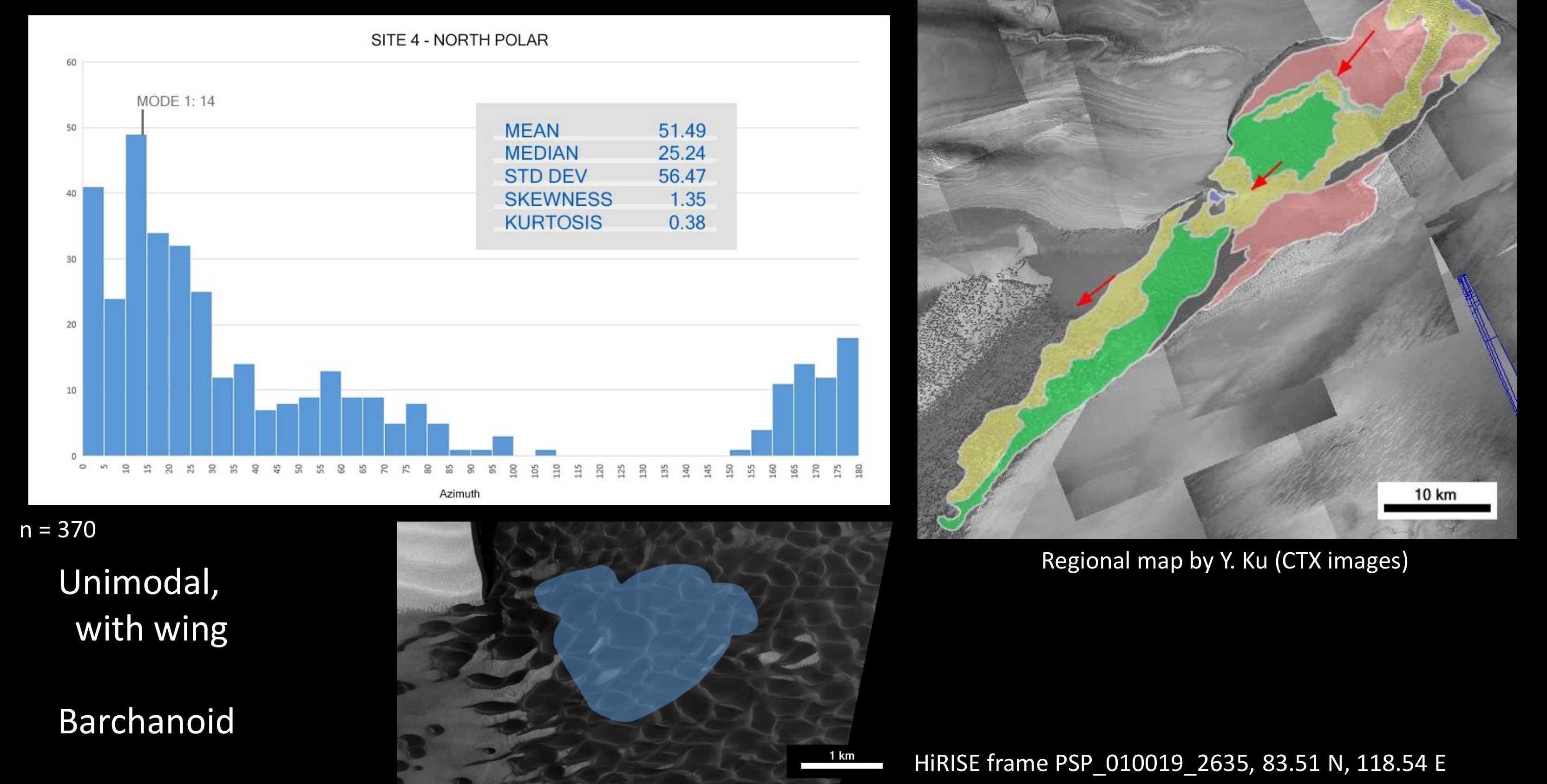




\section{5 - Aonia Terra}

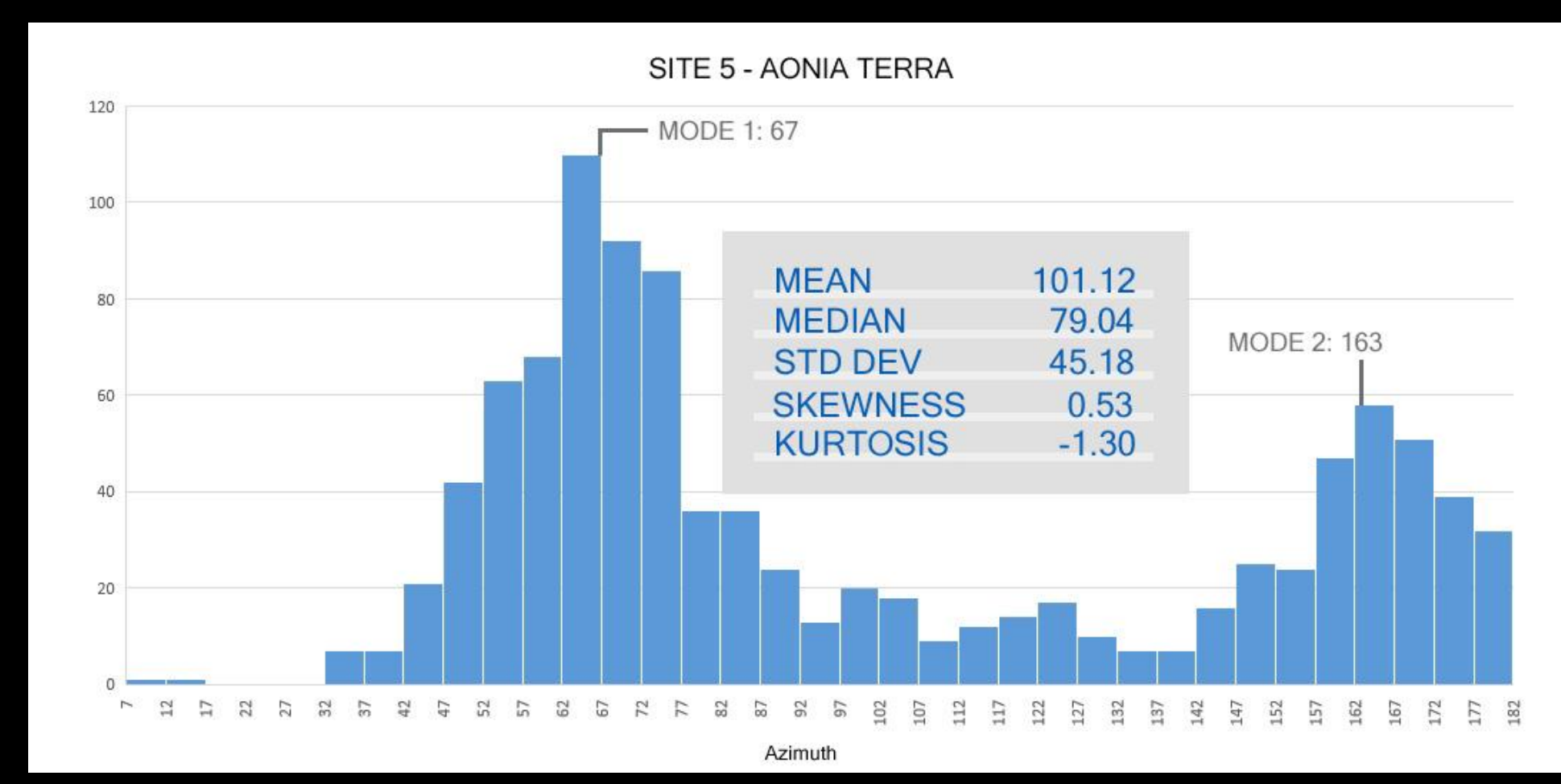

$n=1112$

Bimodal, with wing

Transverse

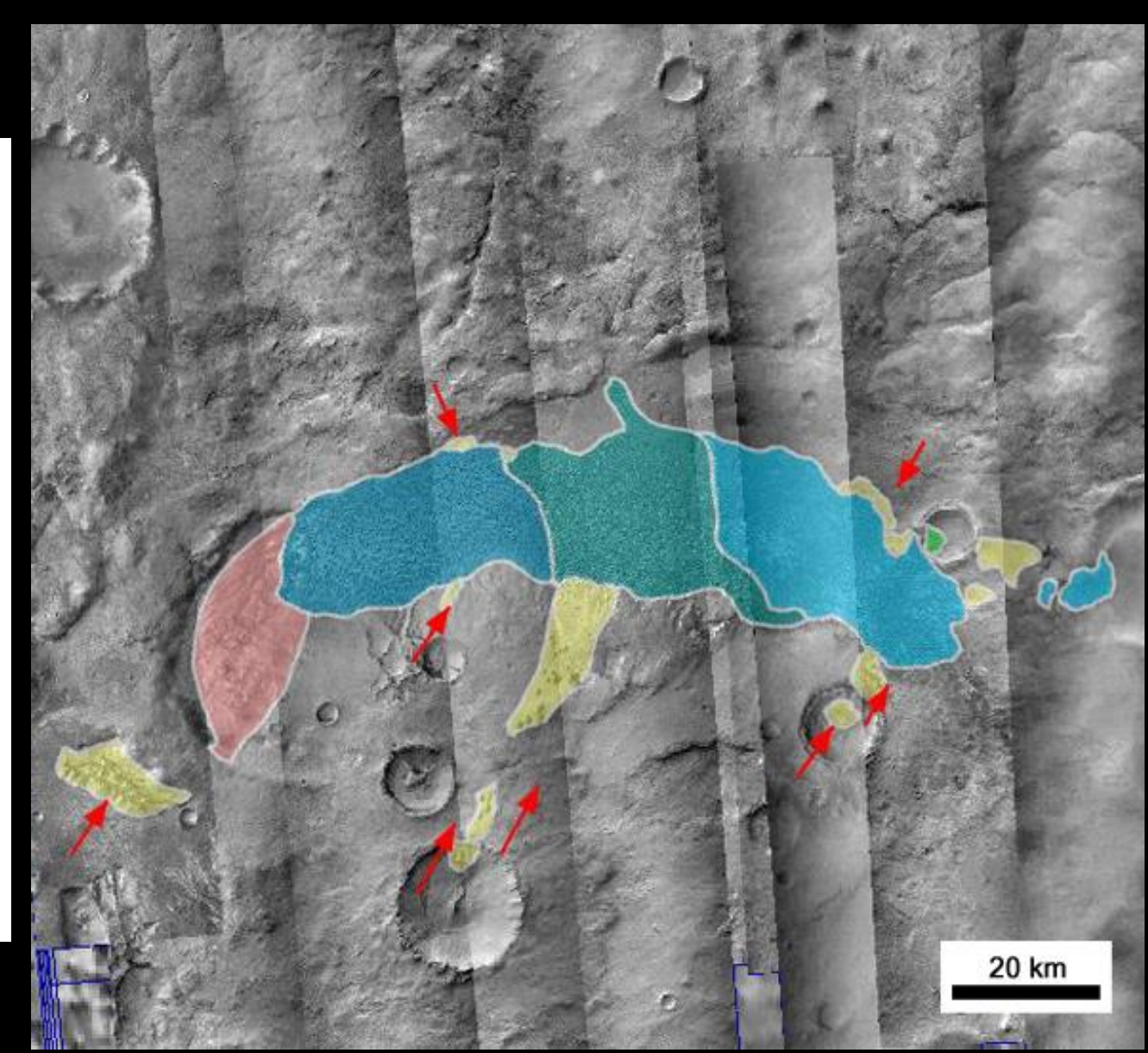

Regional map by Y. Ku (CTX images) 


\section{6 - Ius Chasma}
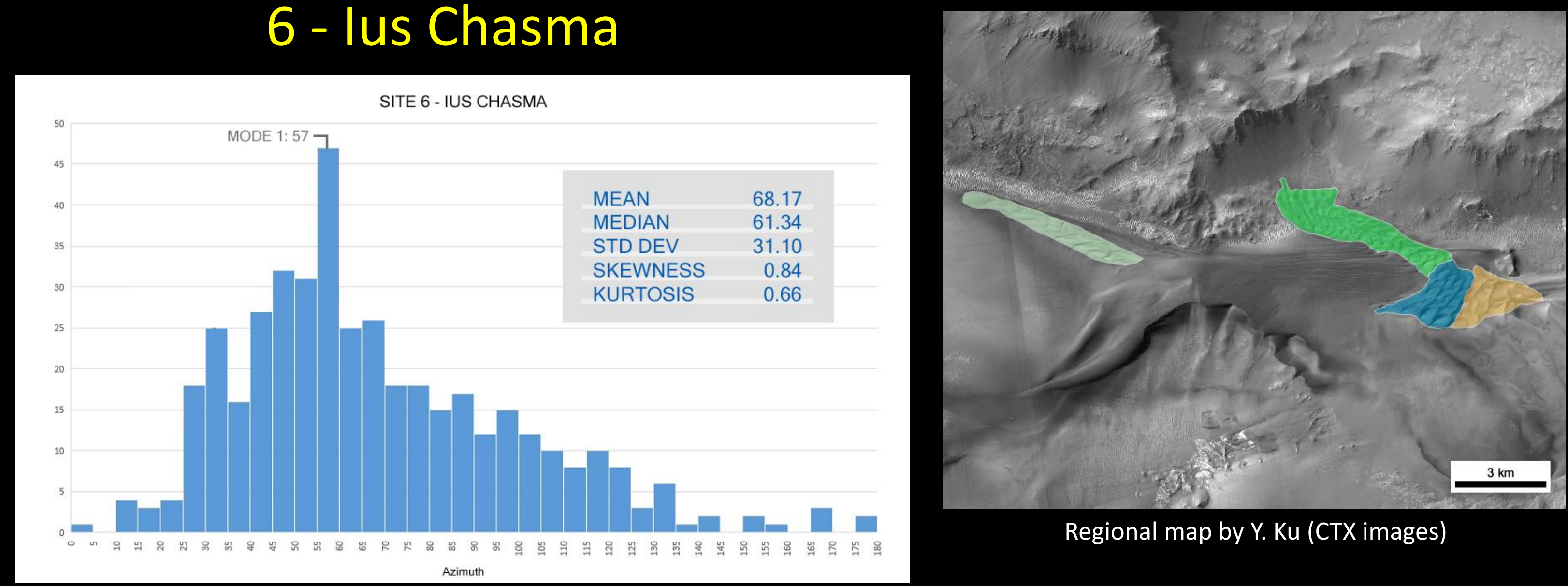

Regional map by Y. Ku (CTX images)

$n=422$

Unimodal, with pronounced wing

Transverse ridge 


\section{7 - Arabia Terra}

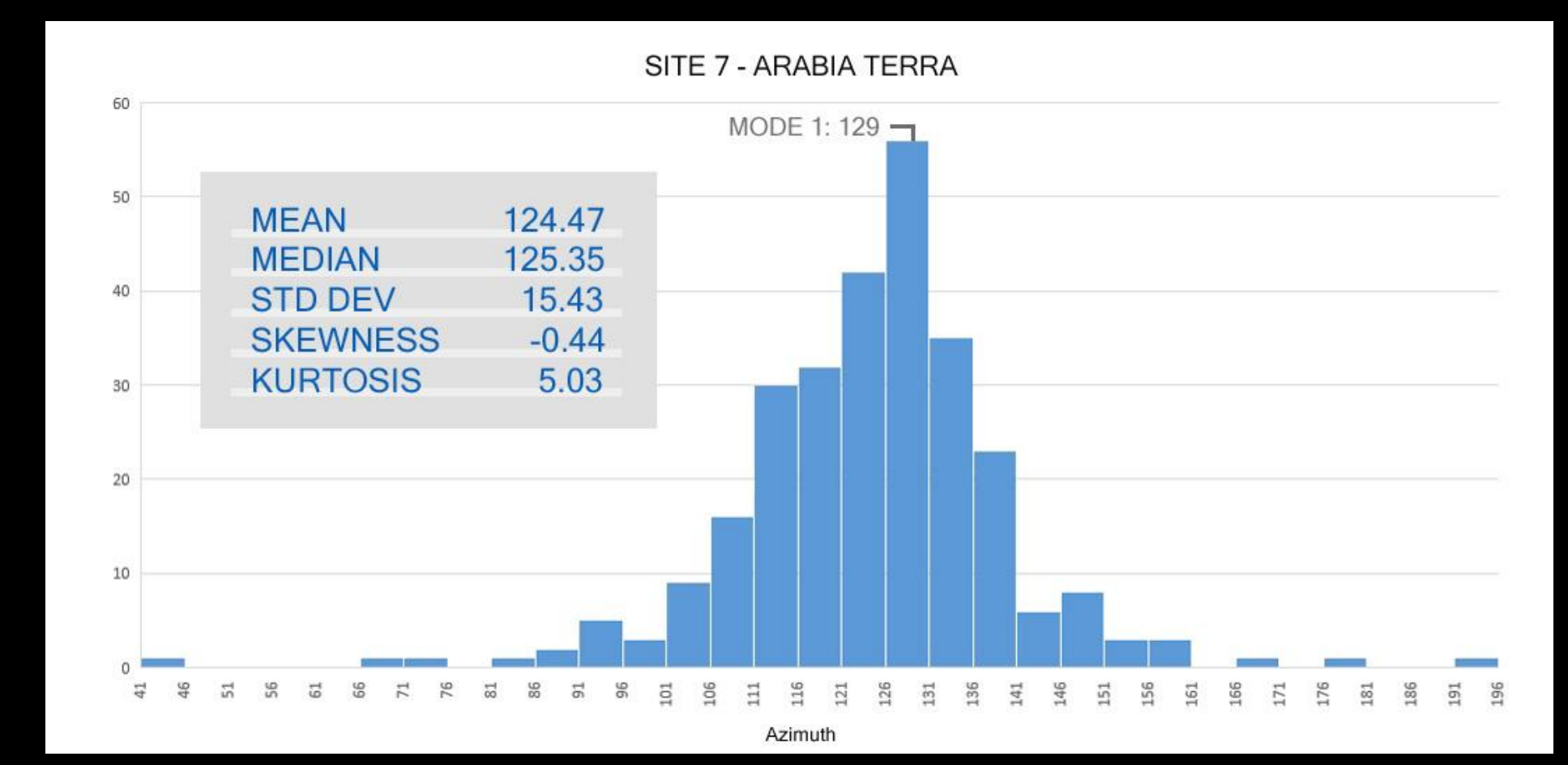

$n=279$

Unimodal, with wings

Barchan
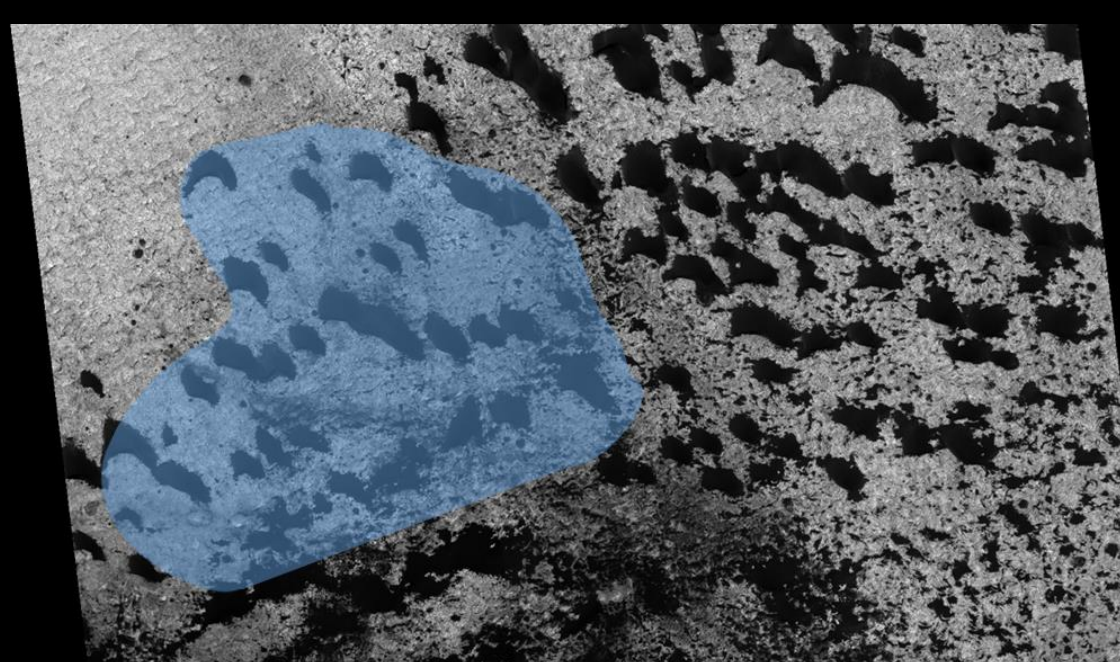

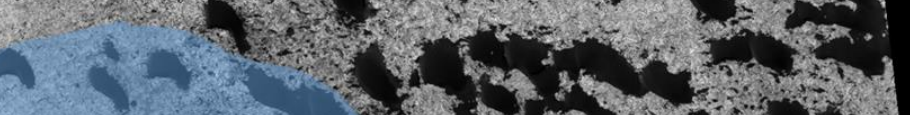
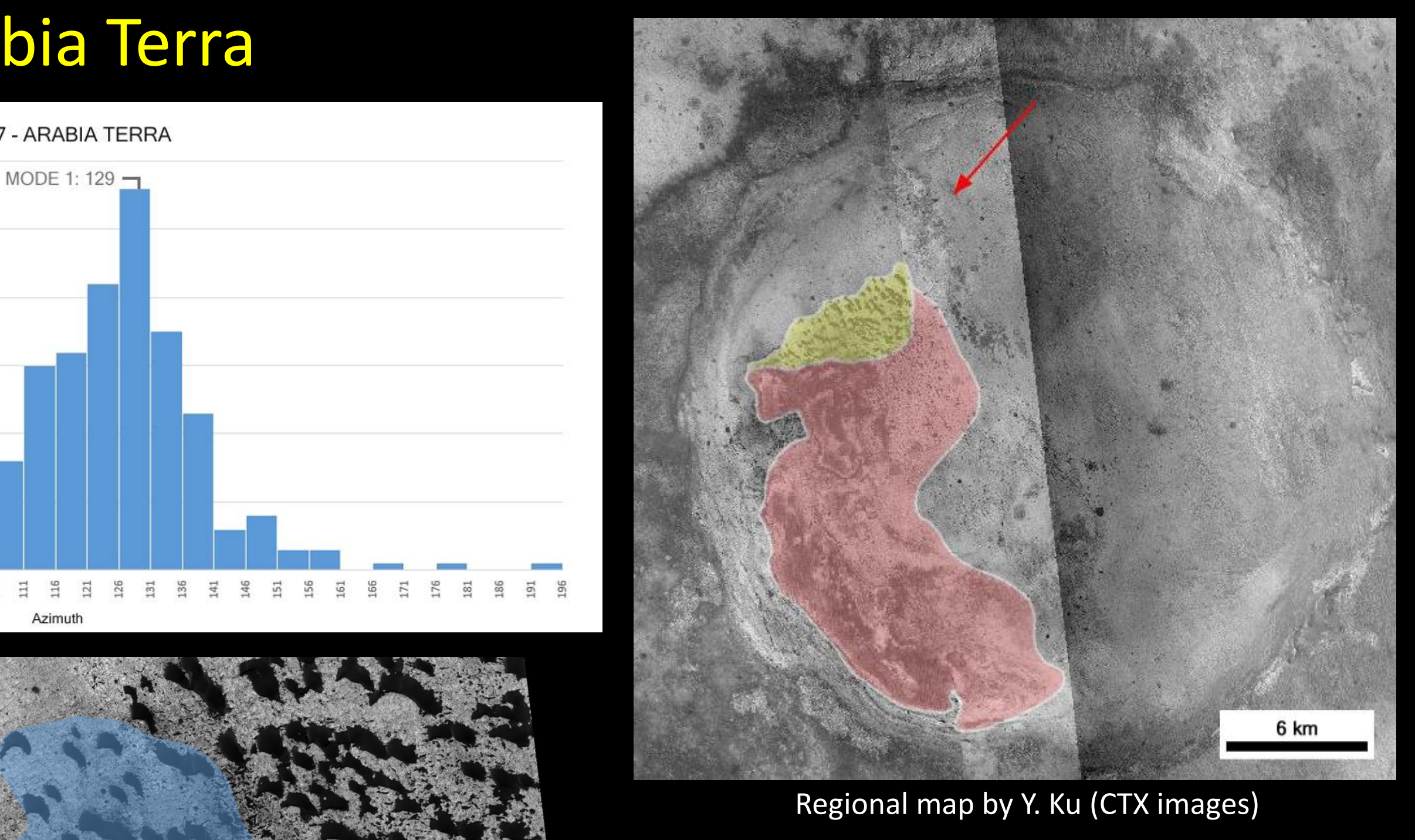

Regional map by Y. Ku (CTX images) 


\section{Conclusions}

Three 'classes' of ripple orientation: unimodal, bimodal, and 'random'

No association with regional setting, elevation, dune type

Dune surface slope direction may be a factor in orienting surface wind 